CLINICAL STUDY

\title{
Gross total resection or debulking of pituitary adenomas improves hormonal control of acromegaly by somatostatin analogs
}

Patrick Petrossians, Liliane Borges-Martins, Consuelo Espinoza ${ }^{2}$, Adrian Daly, Daniela Betea, Hernan Valdes-Socin, Achille Stevenaert ${ }^{1}$, Philippe Chanson ${ }^{2}$ and Albert Beckers

Departments of Endocrinology and ${ }^{1}$ Neurosurgery, CHU de Liège, Sart Tilman, B-4000, Liège, Belgium and ${ }^{2}$ Department of Endocrinology, Hôpital Bicêtre, 78 Rue Du General Leclerc, F-94275, Le Kremlin-Bicêtre, France

(Correspondence should be addressed to A Beckers; Email: albert.beckers@chu.ulg.ac.be)

\begin{abstract}
Introduction: Invasive GH-secreting pituitary adenomas are rarely cured by surgery and although long-term therapy with somatostatin analogs (SSAs) may be employed, hormonal control is achieved in only $60 \%$ of cases. The impact of tumor debulking on subsequent control of acromegaly with SSAs has not been studied previously.

Methods: We studied retrospectively the response to SSA therapy in acromegalic patients before and after incomplete surgical tumor excision. A case review identified 24 acromegalic patients who had received SSA therapy for $\geq 1$ month before and after gross total resection or debulking of adenomas. No patient received radiotherapy or combination treatment with SSAs and dopamine agonists during the study. GH and IGF-I responses to SSAs were recorded pre- and postoperatively. Postoperative SSA therapy was begun after a washout period of $1-3$ months to assess the hormonal effects of the surgery alone.

Results: Before preoperative SSA treatment, 24/24 (100\%) patients had elevated GH levels and IGF-I levels were elevated in 19/21 (90.5\%) patients with recorded values. During preoperative SSA treatment, GH and IGF-I levels were normalized in 7/24 (29.2\%) and 11/24 (45.8\%) patients respectively. Following postoperative washout, GH was controlled in only 3/24 $(12.5 \%)$ patients, while IGF-I was controlled in 8/19 (42.1\%) patients with available data. During the second SSA treatment period, normal GH levels were seen in $13 / 24(54.2 \%)$ patients, while IGF-I control was noted in $18 / 23(78.3 \%)$.

Conclusion: Gross total tumor resection or debulking increases the likelihood of achieving biochemical disease control with SSAs in acromegalic patients with adenomas that were not amenable to complete surgical resection and in whom primary SSA therapy was unable to achieve good biochemical control.
\end{abstract}

European Journal of Endocrinology 152 61-66

\section{Introduction}

Chronic hypersecretion of growth hormone $(\mathrm{GH})$ results in acromegaly, a disease with multiple complications, high long-term morbidity and increased mortality. Three classes of therapy are available for acromegaly: surgical, medical and radiological (1). For patients with microadenomas or uncomplicated macroadenomas, primary therapy is usually adenomectomy, commonly via the transsphenoidal approach. Patients often receive presurgical treatment with a somatostatin analog (SSA) in an effort to improve physical symptoms, to shrink tumors or to influence tumor morphology favorably. For acromegalic patients who are unfit for surgery, or in elderly patients with mild symptoms, primary medical therapy may be advocated, usually with an SSA. The cure rate following surgery in acromegaly is approximately $50-70 \%$; thus many patients who do not achieve surgical cure require subsequent medical or radiation therapy. There is some controversy about the primary treatment of acromegaly in patients with complicated tumors with a low potential for successful surgery (2). This is particularly true in adenomas with laterosellar extension or evidence of invasiveness. Many of these patients will receive SSA therapy in an effort to slow tumor growth and alleviate symptoms; however, the rate of therapeutic failure in normalizing all parameters in this group is significant $(40-60 \%)(3-5)$. The impact of surgery on the hormonal response to SSAs has not 
been studied previously in a series of acromegalic patients with difficult-to-resect tumors. Therefore, we performed a retrospective study of the GH and insulin-like growth factor-I (IGF-I) responses to SSAs before and after subtotal surgical tumor excision.

\section{Patients and methods}

Case records of acromegalic patients from two centers (University Hospital, Liège, Belgium and Bicêtre University Hospital, Le Kremlin-Bicêtre, France) were screened for subjects who had undergone transsphenoidal surgery and who were treated with SSAs before and after surgery. We identified patients who underwent either (i) tumor debulking of an unresectable tumor or (ii) gross total resection that did not lead to complete tumor excision (Table 1). All patients had to have clinically active acromegaly before and after surgery, and only patients for whom sufficient GH and IGF-I data were available during the pre- and post-surgical periods were included. Preoperative SSA treatment was given for at least 1 month in all patients, while postoperative SSA therapy lasted at least 3 months. Patients who received combination treatment with SSAs and dopamine agonists during the study period were excluded. No patient had received radiotherapy before or during the study period. To allow for an adequate washout period, post-surgical hormonal sampling was performed at least 30 days after surgery and the last octreotide administration. Three patients were treated before surgery using long-acting SSAs (lanreotide and lanreotide autogel), and the post-surgical evaluation was done after a 3 month period in these patients.

\section{GH and IGF-I measurements}

GH and IGF-I were measured at four time points: t0: baseline data at diagnosis; $\mathrm{t} 1$ : data during preoperative SSA treatment; ts0: data after surgery and SSA washout; ts1: data during postoperative SSA treatment.

The following hormonal values were selected: the basal GH value pre-SSA therapy, the lowest GH value obtained during SSA therapy and the corresponding IGF-I levels before and during SSA therapy. GH and IGF-I concentrations were measured using commercially available kits. 'Normal' GH cut-off values have been lowered in recent years, with the current literature favoring a value of $2 \mu \mathrm{g} / \mathrm{l}$; thus we chose this threshold for our study (1). Due to the use of different assays, IGF-I values were expressed as a percentage of the upper limit of normal values, normalized for age and sex for each assay. Thus, the cut-off value for normalization of IGF-I was $100 \%$.

\section{Statistical analysis}

The GH and IGF-I data showed the presence of outliers in the higher values of the samples. This deviation from a normal distribution of the samples was confirmed by

Table 1 Patient characteristics and treatment details.

\begin{tabular}{|c|c|c|c|c|c|c|c|c|c|c|c|}
\hline Patient & Sex/age & Diameter & Invasion & Treatment & Dose & $\begin{array}{l}\text { Duration } \\
\text { (months) }\end{array}$ & Surgery & Immunohistology & Treatment & Dose & $\begin{array}{l}\text { Duration } \\
\text { (months) }\end{array}$ \\
\hline 1 & $\mathrm{M} / 36$ & 17 & - & Octr & 300 & 4 & 1 & $\mathrm{GH}, \alpha-\mathrm{SU}$ & Octr & 300 & 2 \\
\hline 2 & $F / 39$ & 32 & L & Octr & 300 & 1 & 2 & GH, PRL & Octr & 300 & 2 \\
\hline 3 & $\mathrm{M} / 48$ & 20 & - & Octr & 600 & 6 & 1 & $\mathrm{GH}, \mathrm{PRL}$ & Octr & 300 & 4 \\
\hline 4 & $\mathrm{M} / 34$ & 26 & - & Octr & 900 & 3 & 1 & $\mathrm{GH}, \mathrm{ACTH}$ & Octr & 1500 & 5 \\
\hline 5 & $\mathrm{~F} / 55$ & 12 & - & Octr & 300 & 1 & 1 & $\mathrm{GH}, \mathrm{PRL}$ & Octr & 200 & 6 \\
\hline 6 & $\mathrm{~F} / 42$ & 25 & - & Lanr & 60 & 5 & 2 & $\mathrm{GH}, \mathrm{PRL}$ & Lanr & 60 & 4 \\
\hline 7 & $\mathrm{M} / 35$ & 26 & $\mathrm{R}$ & Octr & 300 & 3 & 1 & $\mathrm{GH}, \mathrm{PRL}$ & Octr & 300 & 1 \\
\hline 8 & $F / 62$ & 18 & L & Octr & 300 & 5 & 1 & $\mathrm{GH}$ & Octr & 300 & 7 \\
\hline 9 & $\mathrm{M} / 36$ & $<10$ & - & Octr & 1500 & 6 & 1 & $\mathrm{GH}$ & Octr & 400 & 3 \\
\hline 10 & $\mathrm{M} / 38$ & 15 & - & Octr & 1500 & 1 & 1 & $\mathrm{GH}$ & Octr & 300 & 4 \\
\hline 11 & $\mathrm{M} / 44$ & 23 & L & Octr & 300 & 5 & 2 & $\mathrm{GH}$ & Octr & 300 & 12 \\
\hline 12 & $F / 53$ & 14 & $\mathrm{R}$ & Octr & 300 & 5 & 1 & $\mathrm{GH}$ & Octr & 300 & 3 \\
\hline 13 & $F / 36$ & 25 & - & Octr & 300 & 6 & 1 & $\mathrm{GH}, \mathrm{PRL}$ & Lanr & 60 & 12 \\
\hline 14 & $\mathrm{~F} / 59$ & 12 & $L$ & Octr & 300 & 7 & 1 & $\mathrm{GH}, \mathrm{PRL}$ & Octr LAR & 20 & 5 \\
\hline 15 & $\mathrm{M} / 38$ & 16 & - & Octr & 500 & 3 & 1 & $\mathrm{GH}, \mathrm{PRL}$ & Lanr & 90 & 3 \\
\hline 16 & F/64 & 31 & - & Octr & 300 & 13 & 2 & $\mathrm{GH}, \mathrm{TSH}$ & Octr & 300 & 17 \\
\hline 17 & $F / 36$ & 8 & - & Octr & 1500 & 6 & 1 & $\mathrm{GH}$ & Octr LAR & 30 & 72 \\
\hline 18 & $F / 49$ & 26 & $\mathrm{R}$ & Octr & 300 & 13 & 1 & $\mathrm{GH}, \alpha-\mathrm{SU}$ & Lanr & 60 & 7 \\
\hline 19 & $\mathrm{M} / 42$ & 30 & $\mathrm{R}$ & Octr & 300 & 9 & 2 & $\mathrm{GH}, \mathrm{PRL}, \alpha-\mathrm{SU}$ & Octr & 300 & 36 \\
\hline 20 & $F / 39$ & 30 & - & Octr & 300 & 5 & 2 & $\mathrm{GH}, \mathrm{PRL}$ & Octr & 300 & 4 \\
\hline 21 & $M / 15$ & $<10$ & $\mathrm{R}$ & Lanr & 60 & 52 & 2 & $\mathrm{GH}, \alpha-\mathrm{SU}$ & Lanr & 60 & 33 \\
\hline 22 & $F / 35$ & 25 & $\mathrm{~L}$ & Octr & 1500 & 10 & 2 & $\mathrm{GH}, \mathrm{PRL}$ & Octr & 1500 & 3 \\
\hline 23 & $F / 19$ & 24 & $\mathrm{~L}$ & Octr & 1500 & 5 & 2 & $\mathrm{GH}, \mathrm{PRL}$ & Octr & 1500 & 4 \\
\hline 24 & $\mathrm{M} / 41$ & 22 & $\mathrm{~L}$ & Lanr AG & 90 & 4 & 1 & $\mathrm{GH}, \mathrm{PRL}$ & Lanr & 60 & 5 \\
\hline
\end{tabular}

Age: age at diagnosis. Diameter: maximal diameter in $\mathrm{mm}$. Invasion: L/R = left/right cavernous sinuses. Treatment/Dose: Octr: octreotide ( $\mu \mathrm{g} / \mathrm{day})$, Lanr: lanreotide (mg/month), Octr: LAR: octreotide LAR (mg/month), Lanr AG: lanreotide autogel (mg/month). Surgery: $1=\mathrm{gross}$ total resection, $2=$ debulking. $\mathrm{PRL}$, prolactin; ACTH, adrenocorticotropin; TSH, thyrotropin; $\alpha$-SU, $\alpha$-subunit. 
quantile-quantile plots and the Kolmogorov-Smirnov test, showing that the distribution was non-normal.

Therefore, the data were described using the trimmed mean $\left(\chi_{\mathrm{t}}\right)$ with a trimming factor of 0.2 . The standard error $\left(S e_{w}\right)$ of the distribution of the trimmed means was calculated using the Winsorised variance $\left(S_{w}^{2}\right)$ of the sample for a $95 \%$ confidence interval. Due also to the deviation from the normal distribution, $\mathrm{GH}$ and IGF-I values during SSA treatment, before and after surgery were compared using the percentile $t$ bootstrap method for trimmed means, offering a more robust and unbiased appreciation of the difference between the means $(6,7)$. Chi-squared tests were also used to compare the numbers of patients achieving safe IGF-I levels under SSAs before and after surgery. Data analysis was performed with the $\mathrm{R}$ statistical software (8), with the additional Rand-Wilcox-Randfunv package for the standard error and bootstrap routines (9).

\section{Results}

The study population consisted of 24 acromegalic patients. The patients' demographic and disease characteristics are shown in Table 1 . The mean durations of SSA treatment before and after surgery were $7.4 \pm 10.0$ and $10.6 \pm 15.9$ months $(P=N S)$ respectively.

\section{GH responses}

The GH responses before and after surgery and SSAs are shown in Fig. 1 and Table 2. Lowest pretreatment $\mathrm{GH}$ values at $\mathrm{t} 0$ showed a wide range $(2.6-150 \mu \mathrm{g} / \mathrm{l})$ with a mean value of $22.2 \mu \mathrm{g} / \mathrm{l}\left(S e_{w}\right.$ : 3.6). Nadir $\mathrm{GH}$ levels were higher than $2 \mu \mathrm{g} / \mathrm{l}$ in all patients at $\mathrm{t} 0$. At the end of the first SSA treatment period (t1), nadir $\mathrm{GH}$ levels were significantly lowered to a mean value of $6.2 \mu \mathrm{g} / \mathrm{l}\left(S e_{w}: 1.5\right.$, range $\left.0.4-35.7 \mu \mathrm{g} / \mathrm{l}\right)$. Of the 24 patients, seven $(29 \%)$ had a nadir GH less than $2 \mu \mathrm{g} / \mathrm{l}$. After surgery, and following a washout period, the mean nadir $\mathrm{GH}$ was $6.7\left(\mathrm{Se}_{\mathrm{w}}\right.$ : 0.8 , range $0.9-$ $32.1 \mu \mathrm{g} / \mathrm{l})$. Only three patients $(12.5 \%)$ had nadir $\mathrm{GH}$ levels of less than $2 \mu \mathrm{g} / \mathrm{l}$. During the second SSA treatment period, $\mathrm{GH}$ level nadirs were further decreased to a mean of $2\left(S e_{w}: 0.7\right) \mu \mathrm{g} / \mathrm{l}$ (range $0.2-18.6 \mu \mathrm{g} / \mathrm{l}$ ) and $\mathrm{GH}$ levels were normalized in 13 patients $(54 \%)$. The nadir GH values achieved during SSA treatment were significantly lower after surgery than before $(P<0.01)$. Taking patients individually, cut-off $\mathrm{GH}$ values of $2 \mu \mathrm{g} / \mathrm{l}$ were achieved in $29.2 \%$ of patients at $\mathrm{t} 1$, and in $54.2 \%$ of patients at ts 1 . The mean $\left(\chi_{\mathrm{t}}\right)$ reduction in $\mathrm{GH}$ with SSAs before surgery was $69 \%$ $\left(S e_{w}: 6.9\right)$, which was similar to that obtained with the postoperative SSA treatment $\left(69 \%, S e_{w}: 6.5\right.$; $P=0.99)$.

\section{IGF-I responses}

The IGF-I levels before and after surgery and SSA therapy are shown in Fig. 2 and Table 2. The mean IGF-I level at t0 was $203 \%\left(S e_{w}: 16\right.$, range $77-$ $737 \%)$. This decreased to $106 \%$ of normal $\left(S e_{w}: 14\right.$, range $37-647 \%$ ) at $\mathrm{t} 1$. After surgery and washout (ts0), the mean IGF-I level was $158 \%\left(\mathrm{Se}_{w}\right.$ : 17 , range $70-316 \%)$. The second course of SSA therapy reduced the mean IGF-I to $78 \%\left(S e_{w}: 9\right.$, range $\left.20-154 \%\right)$. IGF-I values achieved during SSA treatment were significantly lower after surgery than before $(P<0.01)$. The number of patients who achieved safe IGF-I levels during SSAs was significantly higher after surgery. At $\mathrm{t} 1,11 / 24(46 \%)$ patients achieved normal IGF-I levels, which rose to $18 / 23(78 \%)$ patients at ts 1 $\left(\chi^{2}\right.$ test, $\left.P=0.047\right)$.

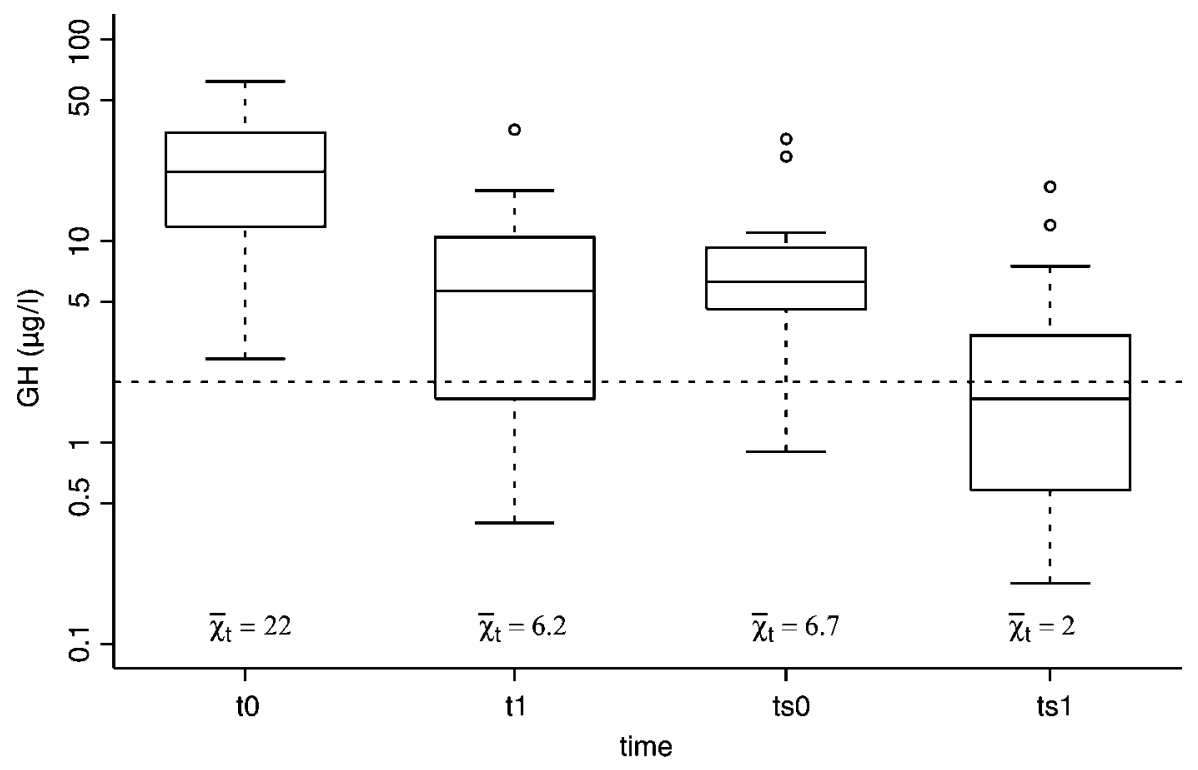

Figure 1 Box and whisker plots of $\mathrm{GH}$ levels (logarithmic) at the four time points. The box plots represent the median and the interquartile range; the whiskers represent the extremes of data ranges. Outlying data points are plotted individually. The horizontal dashed line represents the normal $2 \mu \mathrm{g} / \mathrm{l}$ cut-off value. Trimmed means are indicated under each box. 
Table 2 Individual GH and IGF-1 values for all patients at the four study time points.

\begin{tabular}{|c|c|c|c|c|c|c|c|c|}
\hline \multirow[b]{2}{*}{ Patient } & \multicolumn{2}{|c|}{ to } & \multicolumn{2}{|c|}{ t1 } & \multicolumn{2}{|c|}{ ts 0} & \multicolumn{2}{|c|}{ ts1 } \\
\hline & $\begin{array}{c}\mathrm{GH} \\
(\mu \mathrm{g} / \mathrm{l})\end{array}$ & $\begin{array}{c}\text { IGF-I } \\
(\%)\end{array}$ & $\begin{array}{c}\mathrm{GH} \\
(\mu \mathrm{g} / \mathrm{l})\end{array}$ & $\begin{array}{l}\text { IGF-I } \\
(\%)\end{array}$ & $\begin{array}{c}\mathrm{GH} \\
(\mu \mathrm{g} / \mathrm{l})\end{array}$ & $\begin{array}{c}\text { IGF-I } \\
(\%)\end{array}$ & $\begin{array}{c}\mathrm{GH} \\
(\mu \mathrm{g} / \mathrm{l})\end{array}$ & $\begin{array}{c}\text { IGF-I } \\
(\%)\end{array}$ \\
\hline 1 & 15.5 & 164 & 5.7 & 168 & 5.6 & - & 0.6 & - \\
\hline 2 & 30 & 131 & 17.8 & 107 & 26.3 & 82 & 3.9 & 81 \\
\hline 3 & 10 & - & 1.4 & 526 & 4.7 & 89 & 0.6 & 105 \\
\hline 4 & 35.1 & 263 & 2.7 & 105 & 6 & 316 & 2.9 & 150 \\
\hline 5 & 16 & 227 & 1 & 59 & 8.2 & 150 & 1.5 & 80 \\
\hline 6 & 62 & - & 9.8 & 169 & 6.2 & 184 & 2.9 & 92 \\
\hline 7 & 34 & 258 & 1.13 & 132 & 4.5 & - & 0.2 & 65 \\
\hline 8 & 16.8 & 190 & 12 & 118 & 6.6 & 168 & 2.7 & 82 \\
\hline 9 & 12.9 & 211 & 5.6 & 200 & 7.4 & 253 & 1.6 & 74 \\
\hline 10 & 10 & 179 & 3.4 & 74 & 1.3 & - & 0.2 & 42 \\
\hline 11 & 50 & 133 & 0.7 & 117 & 1.1 & 129 & 1 & 48 \\
\hline 12 & 21.8 & 180 & 6.7 & 62 & 9.1 & 84 & 1.7 & 44 \\
\hline 13 & 48 & - & 10.3 & 82 & 8 & 144 & 5.5 & 81 \\
\hline 14 & 7.9 & 164 & 0.8 & 37 & 5.8 & 76 & 0.2 & 34 \\
\hline 15 & 9.3 & 737 & 5.3 & 647 & 0.9 & 90 & 0.4 & 100 \\
\hline 16 & 2.6 & 85 & 0.4 & 58 & 3.1 & 70 & 0.56 & 20 \\
\hline 17 & 27.3 & 300 & 16.1 & 136 & 10.1 & - & 2.5 & 141 \\
\hline 18 & 150 & 250 & 3.2 & 77 & 6.2 & 106 & 0.6 & 27 \\
\hline 19 & 28.5 & 139 & 9 & 147 & 10 & 122 & 12 & 154 \\
\hline 20 & 12 & 112 & 1.9 & 68 & 3.6 & 74 & 0.3 & 58 \\
\hline 21 & 26.1 & 184 & 35.7 & 63 & 11 & 197 & 5.5 & 99 \\
\hline 22 & 35.8 & 173 & 17.7 & 95 & 32.1 & - & 18.6 & 94 \\
\hline 23 & 11.57 & 77 & 9.9 & 56 & 9.4 & 74 & 7.5 & 47 \\
\hline 24 & 22.5 & 240 & 10.6 & 144 & 6.38 & 182 & 2.9 & 105 \\
\hline
\end{tabular}

t0: data at diagnosis. $\mathrm{t} 1$ : data at the end of the preoperative SSAs trial. ts0: data after surgical debulking. ts1: data at the end of the postoperative SSAs trial. IGF-I values are expressed as \% of upper normal limit. GH cutoff value: $2 \mu \mathrm{g} / \mathrm{l}$. IGF-I cut-off value: $100 \%$.

\section{Discussion}

The optimal choice of treatment for acromegalic patients with varying disease severity has been a subject of continuing discussion. Surgical treatment allows the complete removal of the adenoma in $50-70 \%$ of cases, and may definitively cure the patient. It follows, however, that in a sizeable proportion of cases, complete removal of the adenoma is not possible, due to extrasellar extension or invasion of the tumor. Bone and/or dural invasion or intracavernous extension of the tumor reduces the surgical cure rate in acromegaly. As macroadenomas represent $60-80 \%$ of $\mathrm{GH}$-secreting adenomas, this is a significant therapeutic challenge (5). Primary medical treatment is considered an adjunct to or an alternative to surgery in patients with difficult-to-resect tumors. SSAs, such as octreotide and lanreotide, often in their long-acting depot formulations, are a useful option to achieve clinical improvements and potentially shrink tumors. These compounds often allow good control of GH secretion in patients not cured by surgery or in cases where surgery is contraindicated $(1,5)$. The GH antagonist, pegvisomant is also useful in patients who have an inadequate response to SSA treatment $(10,11)$. The therapeutic value of investigational agents, such as chimerical compounds that act on somatostatin and dopamine receptors, remains to be proven. Radiotherapy is third-line therapy when GH secretion is not sufficiently controlled by surgery and medical treatment, but is of limited use due to the potential for long-term side effects resulting from the irradiation of neighboring structures. As long-term treatment by SSAs permits the normalization of GH and IGF-I in a substantial

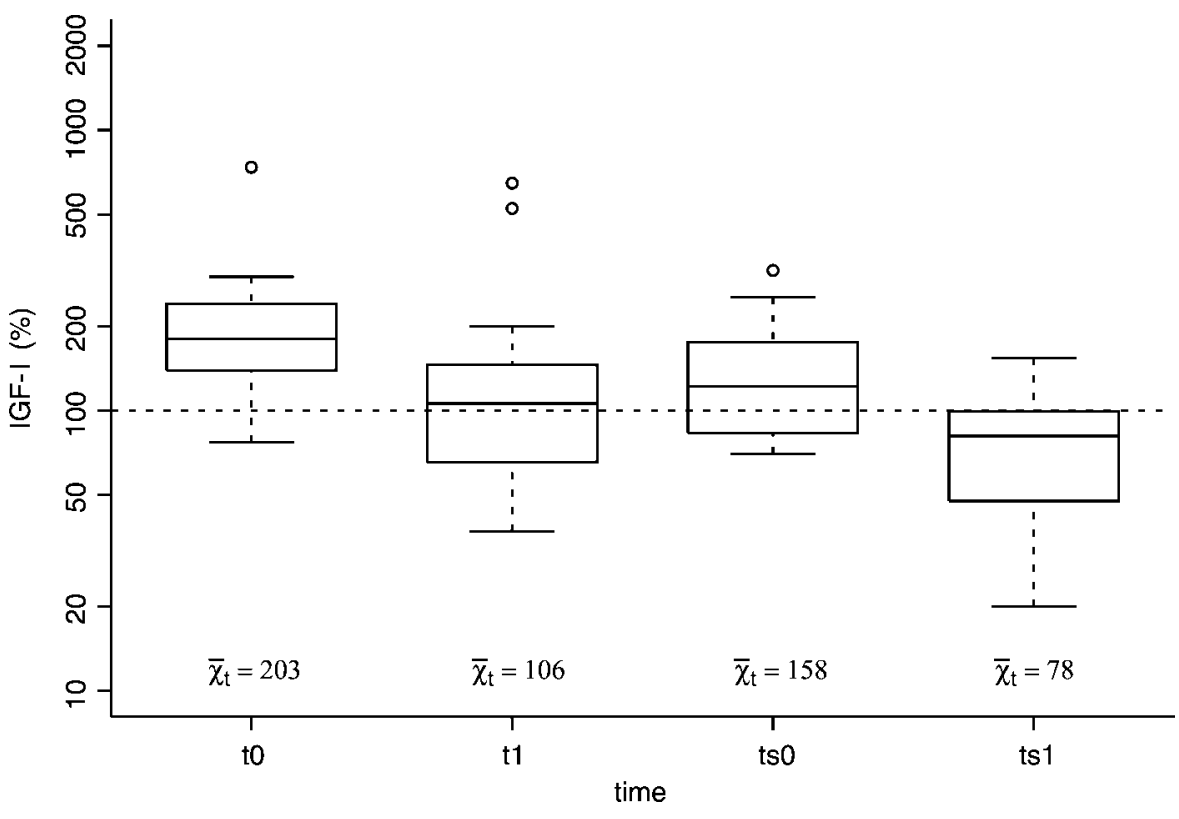

Figure 2 Box and whisker plots of IGF-I levels (logarithmic) at the four time points. Data are expressed as a percentage of the upper limit of normal values, normalized for age and sex for each assay. The box plots represent the median and the interquartile range; the whiskers represent the extremes of data ranges. Outlying data points are plotted individually. The horizontal dashed line represents the normal $100 \%$ cut-off value. Trimmed means are indicated under each box. 
number of cases (40-60\%) (12), some physicians may opt to treat patients suffering from extrasellar macroadenomas with SSAs when compression of adjoining structures is not present $(12-17)$. Whether or not surgery improves the outcome of medical therapy with SSAs has not been studied previously. In studies of octreotide as primary treatment compared with patients who had undergone pituitary surgery or irradiation and who were receiving octreotide as second-line treatment, octreotide was equally effective (14). We hypothesized that by reducing tumor mass and decreasing basal GH secretion, the subsequent control of GH and IGF-I levels with SSAs could be improved. This hypothesis is consistent with longterm trials that show a better control of $\mathrm{GH}$ and IGF-I with SSAs when initial GH levels are lower (12). Patient inclusion for our study was facilitated by the fact that most acromegalic patients who undergo surgery at our centers are pretreated with SSAs for a period of at least 3 months to improve general health and facilitate surgical adenoma resection (18). The results of our study suggests that surgical reduction of the pituitary tumor mass can enhance the possibility of achieving postoperative hormonal control with SSA treatment. In this series, preoperative SSA therapy was associated with adequate GH and IGF-I responses in approximately 29 and $46 \%$ of patients respectively. In the case of $\mathrm{GH}$, this response rate is lower than would be expected from published series, but is not surprising given that patients were suffering from large, invasive or difficult-to-resect tumors. Of the 17 patients who did not normalize $\mathrm{GH}$ values with preoperative medical therapy, six achieved normal GH levels with postoperative SSA treatment. Of the 13 patients who did not normalize IGF-I values with preoperative medical therapy, seven achieved normal IGF-I levels with postoperative SSA therapy. The magnitude of the decrease in GH with SSA therapy following surgical debulking was virtually identical to that seen before surgery. This indicates that surgical debulking did not have a qualitative impact on the responsiveness of $\mathrm{GH}$ adenoma cells; rather, these results suggest that the magnitude of the effect of SSA on reducing GH secretion in acromegaly is relatively fixed. Thus, a reduction in the baseline GH secretion by surgically debulking increases the likelihood that further reductions in GH secretion achieved by SSAs would bring patients toward acceptable hormonal control, and potentially reduce excess mortality.

In conclusion, this retrospective study shows that in patients with tumors that were not successfully removed surgically and in whom primary medical therapy was unable to produce hormonal control, gross total resection or debulking of the tumor increases the probability of achieving hormonal control with postoperative SSA administration. Even if surgery is unable to cure acromegaly or qualitatively alter the response to SSAs, it can permit a higher percentage of patients to attain safe levels of GH and IGF-I with subsequent medical therapy.

\section{References}

1 Melmed S, Casanueva FF, Cavagnini F, Chanson P, Frohman L, Grossman A, Ho K, Kleinberg D, Lamberts S, Laws E, Lombardi G, Vance ML, Werder KV, Wass J \& Giustina A. Acromegaly Treatment Consensus Workshop Participants. Guidelines for acromegaly management. Journal of Clinical Endocrinology and Metabolism $2002 \mathbf{8 7} 4054-4058$.

2 Fahlbusch R, Honegger J \& Buchfelder M. Surgical management of acromegaly. Endocrinology and Metabolism Clinics of North America $199221669-692$.

3 Freda PU. Somatostatin analogs in acromegaly. Journal of Clinical Endocrinology and Metabolism 200287 3013-3018.

4 Chanson P, Boerlin V, Ajzenberg C, Bachelot Y, Benito P, Bringer J, Caron P, Charbonnel B, Cortet C, Delemer B, Escobar-Jiminez F, Foubert L, Gaztambide S, Jockenhoevel F, Kuhn JM, Leclere J, Lorcy Y, Perlemuter L, Prestele H, Roger P, Rohmer V, Santen R, Sassolas G, Scherbaum WA, Schopohl J, Torres E, Varela C, Villamil F \& Webb SM. Comparison of octreotide acetate LAR and lanreotide SR in patients with acromegaly. Clinical Endocrinology 200053 577-586.

5 Sheppard MC. Primary medical therapy for acromegaly. Clinical Endocrinology $2003 \mathbf{5 8} 387-399$.

6 Wilcox RR. Fundamentals of Modern Statistical Methods, New York: Springer, 2001.

7 Yuen KK. The two sampled trimmed $t$ for unequal population variances. Biometrika 197461 165-170.

8 Ihaka R \& Gentleman R. R: a language for data analysis and graphics. Journal of Computational and Graphical Statistics $1996 \mathbf{5}$ 299-314.

9 Wilcox RR. Introduction to Robust Estimation and Hypothesis Testing. San Diego, CA: Academic Press, 1997.

10 Trainer PJ, Drake WM, Katznelson L, Freda PU, Herman-Bonert V, van der Lely AJ, Dimaraki EV, Stewart PM, Friend KE, Vance ML, Besser GM, Scarlett JA, Thorner MO, Parkinson C, Klibanski A, Powell JS, Barkan AL, Sheppard MC, Malsonado M, Rose DR, Clemmons DR, Johannsson G, Bengtsson BA, Stavron S, Kleinberg DL, Cook DM, Phillips LS, Bidlingmaier M, Strasburger CJ, Hackett S, Zib K, Bennett WF \& Davis RJ. Treatment of acromegaly with the growth hormone-receptor antagonist pegvisomant. New England Journal of Medicine $2000 \mathbf{3 4 2}$ $1210-1211$.

11 van der Lely AJ, Hutson RK, Trainer PJ, Besser GM, Barkan AL, Katznelson L, Klibanski A, Herman-Bonert V, Melmed S, Vance ML, Freda PU, Stewart PM, Friend KE, Clemmons DR, Johannsson G, Stavrou S, Cook DM, Phillips LS, Strasburger CJ, Hackett S, Zib KA, Javis RJ, Scarlett JA \& Thorner MO. Longterm treatment of acromegaly with pegvisomant, a growth hormone receptor antagonist. Lancet 2001358 1754-1759.

12 Bevan JS, Atkin SL, Atkinson AB, Bouloux PM, Hanna F, Harris PE, James RA, McConnell M, Roberts GA, Scanlon MF, Stewart PM, Teasdale E, Turner HE, Wass JA \& Wardlaw JM. Primary medical therapy for acromegaly: an open, prospective, multicenter study of the effects of subcutaneous and intramuscular slow-release octreotide on growth hormone, insulin-like growth factor-I, and tumor size. Journal of Clinical Endocrinology 2002 $874554-4563$.

13 Vance ML \& Harris AG. Long-term treatment of 189 acromegalic patients with the somatostatin analog octreotide. Results of the international multicenter acromegalic study group. Archives of Internal Medicine 1991151 1573-1578.

14 Newman CB, Melmed S, George A, Torigian D, Duhaney M, Snyder P, Young W, Klibanski A, Molitch ME, Gagel R, Sheeler L, Cook D, Malarkey W, Jackson I, Vance ML, Barkan A, Frohman L \& Kleinberg DL. Octreotide as primary therapy for acromegaly. 
Journal of Clinical Endocrinology and Metabolism $1998 \mathbf{8 3}$ 3034-3040

15 Colao A, Ferone D, Marzullo P, Cappabianca P, Cirillo S, Boerlin V, Lancranjan I \& Lombardi G. Long-term effects of depot longacting somatostatin analog octreotide on hormone levels and tumor mass in acromegaly. Journal of Clinical Endocrinology and Metabolism $2001862779-2786$.

16 Baldelli R, Colao A, Razzore P, Jaffrain-Rea ML, Marzullo P, Ciccarelli E, Ferretti E, Ferone D, Gaia D, Camanni F, Lombardi C \& Tamburrano G. Two-year follow-up of acromegalic patients treated with slow release lanreotide $(30 \mathrm{mg})$. Journal of Clinical Endocrinology and Metabolism 200085 4099-4103.
17 Ayuk J, Stewart SE, Stewart PM \& Sheppard MC. Long-term safety and efficacy of depot long-acting somatostatin analogs for the treatment of acromegaly. Journal of Clinical Endocrinology and Metabolism $2002874142-4146$

18 Stevenaert A \& Beckers A. Presurgical octreotide treatment in acromegaly. Metabolism 199645 (8 Suppl 1) 72-74.

Received 5 August 2004

Accepted 5 October 2004 